\title{
Database Design for Data Mining Driven Forecasting Software Tool for Quality Function Deployment
}

\author{
Shivani K. Purohit \\ Manoharbhai Patel Institute of Engineering and Technology ,Nagpur University, Gondia ,India \\ Email: shivani_purohit@rediffmail.com \\ Ashish K. Sharma \\ Manoharbhai Patel Institute of Engineering and Technology ,Nagpur University, Gondia ,India \\ Email:ash5000@ rediffmail.com
}

\begin{abstract}
Efficient Database design is the key part of software development. A properly built database acts as the backbone of the software system and makes enhancing software more easily and quickly. Quality Function Deployment and data mining itself are very gordian processes. Thus, there is strong need of database for handling complex transactions of Quality Function Deployment along with data mining and accessing precise and up-to-date information concerned to this. Forecasting in Quality Function Deployment can be time consuming when computed manually. Hence, development of data mining driven forecasting software tool can give better results and also save time. This paper focuses on the database design for the development of data mining driven forecasting software tool for Quality Function Deployment. Here, first brief discussion on Quality Function Deployment and data mining followed by its concise literature review is presented. Later on, the integrated value chain needed by data mining driven forecasting system for Quality Function deployment is discussed. Then the flow chart illustrating the processes of the software tool is intended. Afterwards the tabulated schemas of logical part of database have been presented. Finally, the ER-diagram for the software and described the relationships among the tables have been designed followed by conclusion. Recognizing the general architecture and structural component of database system will lend a hand to designers and engineers successfully build up and sustain forecasting software tool.
\end{abstract}

Index Terms - Data mining, Database design, Database, Forecasting, Quality Function Deployment (QFD).

\section{INTRODUCTION}

Development of the effective software encompasses through the designing and implementation of a precise database. Databases are tracking mechanisms and designed to ensure accuracy and integrity with the data it tracks ${ }^{[1]}$.A well-designed database can contribute to development of efficient software. It helps in accessing latest and accurate information. A correct design can play vital role in achieving goals in working with database. Hence, it becomes very essential to study and design the architecture as well as components of database for the development of data mining forecasting software tool for Quality Function Deployment.

Quality Function Deployment (QFD) is a customeroriented design tool that aims to meet customer needs in a better way and enhance organizational capabilities, while maximizing company goals ${ }^{[2]}$. QFD is used to promote the idea of new concepts and technology. Its use facilitates the process of concurrent engineering and encourages teamwork to work towards a common goal of ensuring customer satisfaction ${ }^{[3]}$. Customer requirement is the heart of QFD; it's a primary input to QFD. In today's rapid changing world customer requirements will also be dynamic. As customer requirements may be different while designing and may be different while the product is in market. Thus, due to this time lag problem, forecasting becomes necessity in QFD. Forecasting future values would be beneficial in making the future plans and can be helpful in taking the preventive measures for the future situation.

It can be better achieved using the data mining technique of forecasting. Data mining has been proven effective approach of forecasting. Data mining, also called Knowledge Discovery in Databases (KDD), is the field of discovering novel and potentially useful information from large amounts of data ${ }^{[4]}$.The basic concept of data mining is using the historic data for predicting the future values. Data mining offers the variety techniques of forecasting; such as cluster analysis, decision trees, categorization analysis, visualization, time series analysis, hybrid approaches, linkage analysis, and neural network. As the concept of data mining uses the vast amount of data, hence the proper storage of these data is required. Therefore need for designing the database arises.

The major issues of designing a database for data mining driven forecasting software tool for Quality Function Deployment are 
- Handling of QFD calculations;

- Handling of forecasts calculated by using the various data mining techniques.

- $\quad$ Supporting user interface at the database level (e.g., navigation, store layout, hyperlinks);

- $\quad$ Schema evolution (e.g., new products, new period etc);

- Data evolution (e.g., changes in specification and description, naming, rating etc.);

- Handling meta data;

- Capturing data from user's console.

In this paper, we presented the general discussion on QFD and Data mining, brief literature review, overview of value chain of forecasting software tool, tabular description of the schema used for designing the database followed by ER-diagram and lastly conclusion.

\section{QUALITY FUNCTION DEPLOYMENT}

Quality Function Deployment (QFD) is customer oriented cross functional planning tool used to enhance organizational capabilities, while maximizing company goals. QFD was originally designed and implemented by Yoji Akao in the late 1960. Akao (1990) defined it as "a method for developing a design quality aims at satisfying the customer and then translating the customer's demands into design targets and major quality assurance points to be used throughout the production stage" "[5]. Its application supports the process of concurrent engineering and promotes teamwork to work towards a common goal of verifying customer satisfaction.QFD involves intelligent transfer of Voice Of Customer (VOC) and customer requirements into proper design requirements i.e internal language of company, designers and engineers. Lockamy and Khurana (1995) explained the design benefits of QFD as (i) fewer and early design changes, (ii) less time in developments, (iii) fewer startup problems, (iv) lower start-up costs, (v) fewer field problems, (vi) more satisfied customers, and (vii) the identification of comparative strengths and weaknesses of products with respect to competition. ${ }^{[6]}$

QFD is one of the most promising tools to satisfy the customers and to convert customers' requirements into design aims. There are four phases of QFD process : (I) product planning: House of Quality (HOQ), (II) product design: parts deployment, (III) process planning, and (IV) process control (Fig 1) ${ }^{[7]}$. Product planning matrix involves the determination of customer requirements which are then translated into design requirements. In product design phase, the potential features of product are related to the delivery of performance characteristic. In the third and fourth phase, process characteristics and production requirements are related to engineering and marketing characteristics.

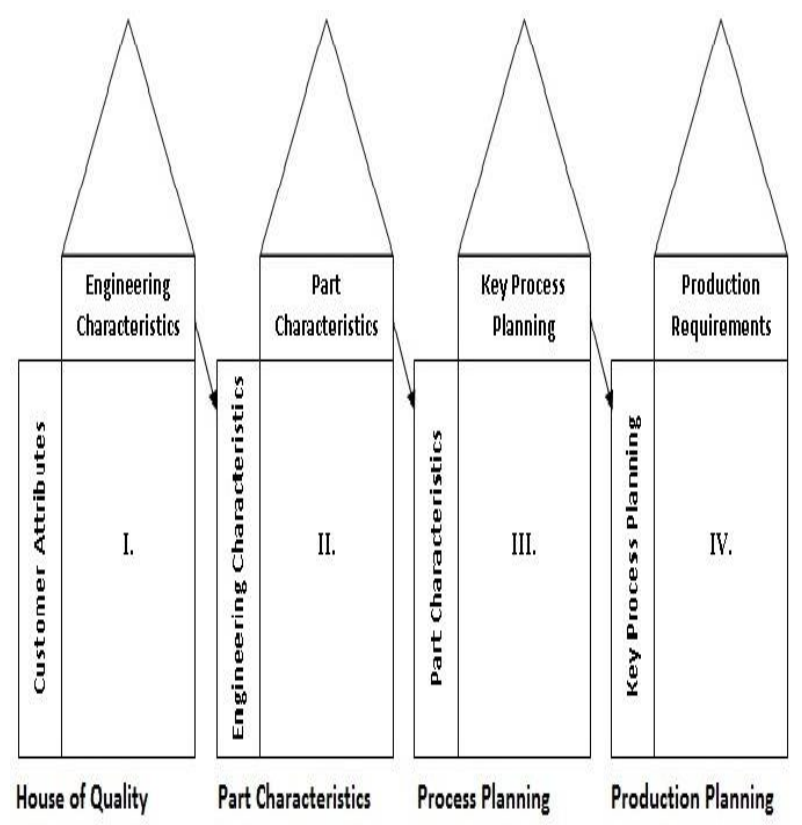

Fig. 1. Phases of $\mathrm{QFD}^{[7]}$

\section{A. House of Quality}

House of Quality (HOQ) is the first p hase and plays very crucial role in managing QFD processes. The majority of QFD applications focuses on HOQ and end with its completion. House of Quality (HOQ) was named by Hauser and Clausing (1988). A HOQ consists of horizontal rows of What, representing customer requirements and vertical columns of How, denoting ways of achieving them ${ }^{[8]}$. It starts with a "What-How" Matrix that recognizes the needs of the customer. These customer requirements are shown on the left part of the HOQ. The ceiling of the House shows the design or design requirements. The body of the House exhibits the co-relationships between the customer requirements and design requirements ${ }^{[9]}$. Though HOQ can be modeled using different steps. Here we are using 6-step HOQ introduced by Zaim and Sevkli. They explained it as follows ${ }^{[10]}$ :

Followings are the steps of 6-step HOQ:

Step 1: Identifying Customer Requirements- The first step of QFD begins with identification of what customer wants from a consumer product.

Step 2: Customer Competitive Evaluations- Customer competitive evaluation systematizes a competitive or deliberate judgment of the business. It consists of ten columns.

Column 1: Satisfying customer requirements at the same time is not possible for an organization, thus prioritization of requirements becomes necessary. It is known as "Rate of Importance". 


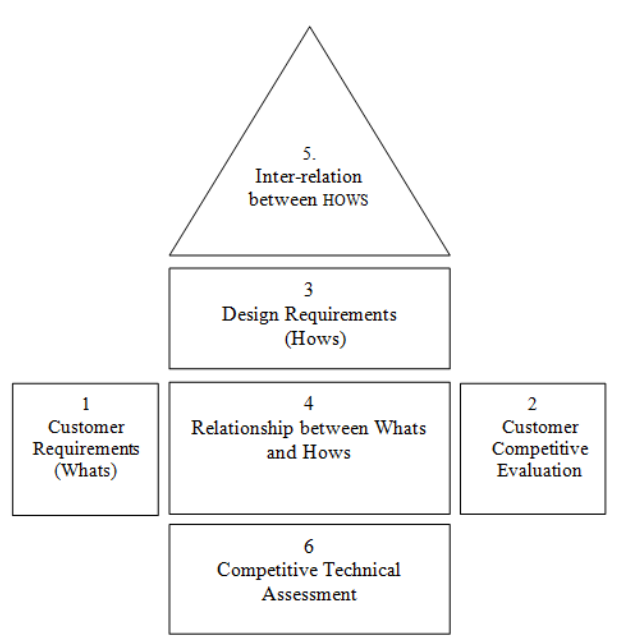

Fig. 2. Six step HOQ for QFD[10]

Column 2: This column represents the current performance of the product A considering the quality characteristics i.e. design requirements.

Column 3, 4, 5: This column signifies the assessment of the competitor's product of the reviewing company.

Column 6: This column indicates the position of the consumer product against its competitors.

Column 7: This column represents what improvement is required in the product. It is achieved by dividing the planned quality target levels by the current quality levels. This is called as "Rate of Improvement".

Column 8: This column shows which feature of the product make sure competitive advantage for the company against its competitor and is named as "Sales Point".

Column 9: This column calculates the Raw weight by multiplying Rate of Importance, Improvement Ratio and Sales Point.

Therefore,

Raw weight $=$ Rate of Importance* Improvement Ratio * Sales Point.

Column 10: Last column is determined by converting the Raw weight to the percentage.

Step 3: Determining Design Requirements- In this stage the customer requirements are translated into appropriate design requirements. These design requirements should satisfy the customer requirement.

Step 4: Co-Relationship between Whats and HowsThis step assembles the relationship between Whats and Hows, i.e customer requirements vs. design requirements.

Step 5: Inter-relationship between design requirements- The roof of the house is designed to interrelate the "hows" against each other.

Step 6: Competitive Technical Assessment- It calculates the weight for each design requirement called as "Column Weight". Calculating column weight is important to know that which design requirements are to be considered first i.e. the design requirements are prioritized.

\section{DATA MINING}

Data Mining (DM) is an important component of the emerging field of knowledge discovery in databases (KDD). Data mining may be defined as "the exploration and analysis, by automatic or semiautomatic means, of large quantities of data in order to discover meaningful patterns and rules". ${ }^{[11]}$ Data mining means discovery of new meaningful information from huge amount of data. It is the concept which uncovers any novel information from accumulated data rather than verifying the earlier set hypothesis. In contradiction of typical statistical methods, data mining techniques discover significant information without demanding a priori hypotheses, and are often more influential, flexible, and proficient for investigative analysis than the statistical techniques.

By and large, there are two types of data mining tasks: descriptive data mining tasks that describe the general properties of the existing data and predictive data mining tasks that attempt to do predictions based on inference on available data ${ }^{[4]}$. The most frequently used techniques in data mining are: Artificial Neural Networks, Genetic Algorithms, Rule Induction, Nearest Neighbor method, Memory-Based Reasoning, Logistic Regression, Discriminant Analysis and Decision Trees.

Data mining has been proven powerful techniques for forecasting. It offers many techniques for forecasting such as time series techniques, regression, clustering, artificial neural network etc. Now-a-days, there is tremendous growth in using data mining time series, with researchers attempting to cluster, classify and mine association rules from increasing huge source of data. Time series data accounts for a large fraction of the data stored in financial, medical and scientific databases ${ }^{[12]}$. For prediction of time series data we can use different data mining techniques. Data mining have been applied in many fields such as stock markets, weekly weather reports, annual precipitation, finance, sale forecast and etc. Nevertheless, its application in QFD is rare. Applying data mining techniques on QFD for forecasting future trends of customer requirement can be very beneficial and can give very appropriate results.

\section{LITERATURE SURVEY}

QFD is planning tool that is used to improve the Quality of product and to achieve higher customer satisfaction. Though it is started off with the manufacturing, nowadays it has been applied to several distinct fields. Zheng and Pulli ${ }^{[13]}$ proposed a generic framework based on QFD concepts and practices to improve mobile service design and development. Kazemzadeh, Behzadian, Aghdasi, and Albadvi ${ }^{[14]}$ have proposed a new methodology based on the integration of two marketing research techniques: conjoint analysis and two-stage cluster analysis. They also introduced three indices, namely, the commonality percentage, the cost reduction, and the satisfaction percentage to analyze the results of developing a generic product in comparison with a product family. Lee, Kang, Yang and Lin ${ }^{[15]}$ have 
constructed a framework with two phases for facilitating the selection of engineering characteristics (ECs) for product design. In the first phase, the priorities of ECs is calculated using the super matrix approach of analytic network process (ANP) and the fuzzy set theory integrated with QFD and the second phase utilized the outcome of first phase and other additional goal for constructing multi-choice goal programming model to select the most suitable ECs. Shen, Tan and Xie ${ }^{[16]}$ have conferred the customer satisfaction benchmarking process in QFD and recommended the use of hierarchical benchmarks for strategic competitor selection and decision making. Alemam and $\mathrm{Li}^{[17]}$ proposed an ecodesign method to systematically generate design concepts for the reduction of environmental impacts. The method is based on the integration of quality QFD and functional analysis (FA) at the early design stage. Telang and Vichoray [18] have discussed the development in agricultural tractor brakes by the application of QFD. Customer requirement plays crucial role in QFD processes.

Predicting future customer requirements in QFD can be beneficial for the company to provide better products, enhance their competitiveness in marketplace and increase customer satisfaction. Forecasting future values would be beneficial in making the future plans and can be helpful in taking the preventive measures for the future situation. DM has been proven the powerful approach of forecasting. Hence it can be used to identify future customer requirements. DM has emerged as analysis tool and currently receiving great attention. It is used to perform various tasks such as prediction, classification, clustering, estimation etc. Lots of work has been done in this area. Some of the references are cited here. Zhang and Fang ${ }^{[19]}$ have introduced the idea of the K-means clustering algorithm analysis the advantages and disadvantages of the traditional K-means clustering algorithm elaborates the method of improving the $\mathrm{K}$ means clustering algorithm based on improve the initial focal point and determine the $\mathrm{K}$ value. $\mathrm{Hu}{ }^{[20]}$ has described DM technology used in criminal investigation work and the importance of using ID3 decision tree to structure the Decision Tree algorithm method. Onwubolu ${ }^{[21]}$ has proposed a new design methodology which is a hybrid of differential evolution (DE) and Group Method of Data Handling (GMDH) for self-organizing DM for the prediction of soil moisture in an aspect of hydrology. Hsu, Hsu, Wang and Lin ${ }^{[3]}$ have applied a time seriesbased DM cycle, using sales questionnaire database, to identify future customer needs in QFD for software designers.

Forecasting can be time consuming, when computed manually. Hence, developing the forecasting- software tool can give the better result of forecasting and also save the time. For the development of software tool, there is a strong need of designing the database. Good database design is essential to obtain a sound, consistent database, and for this purpose good database design methodologies are most suitable to achieve the correct design. Some literature about the database designing is cited here. Yang
[22] designed use case diagram and introduced the three layers of frame structure, and the database design for the hotel management system. Dev and Seth ${ }^{[23]}$ proposed a new design of banking Database system of a bank using the modern MDA approach of software engineering to improve the maintainability, portability and flexibility. Umoh, Nwachukwu, Umoh, and Isong ${ }^{[24]}$ designed, implemented and analyzed a web-based database management system: an Industrial application based on MySQL DBMS, Java web server and Netbeans as the GUI builder. Casanova, Barbosa, Breitman, Furtado [25] presented a research on database design at PUC-Rio from the early development of the relational model to recent applications of semiotic concepts to the design and specification of information systems. Adusei, Kuljaca and Agyepong ${ }^{[26]}$ outlined the architectural design for the CAD/CADx system and then designed and modeled the mammography database by combining two standards, the Breast Imaging Reporting and Data System(BI-RADS). Khan and Saber ${ }^{[27]}$ outlined complete database design for the entire Bangladesh Institute of Research and rehabilitation in Diabetes, Endocrine and Metabolic (BIRDEM) hospital. Cushing, Nadkarni, Finch, Fiala \& Hill, Delcambre and Maier ${ }^{[28]}$ designed component-base end user database for ecologists and suggested ways in which communities might share database components. Lu and Cheng ${ }^{[29]}$ designed and implemented a mobile database system for Java phones by using XML. Song and Whang ${ }^{[30]}$, discussed the structure and components of databases for real-world e-commerce systems by illustrating a detailed design of an e-commerce transaction processing system. McCarthy and Dayal [31] has proposed Event-Condition-Action (ECA) rules as formalism for active database capabilities. Finkelstein, Schkolnick and Tiberio ${ }^{[32]}$ described the concepts used in the implementation of Database Design (DBDSGN), an experimental physical design tool for relational databases developed at the IBM San Jose Research Laboratory. $\mathrm{Kwan}^{[33]}$ developed a customized SAS/AF application to facilitate the design of a large research database. Sentarli, Erdursun and Caman $^{[34]}$ presented the quality cost database management system along with its entity relationship, described the workflow behind the system being design and also showed the repetitive part of the client/server multilayer architecture in an application. Ying and Ling, ${ }^{[35]}$ constructed a fundamental spatial database system for Tibet province using Geodatabase model of the ArcSDE and the Oracle database management system.

\section{Database Designing}

The database can be essential part of software that holds the most important information required by an application. The effectiveness of databases derives from the fact that from one single, comprehensive database much of the information relevant to a variety of organizational purposes may be obtained ${ }^{[36]}$. A welldesigned database is necessity to most applications. Structuring your application with correct database design 
ensures the ease of enhancement as requirements changes and application grows. Correctly structured database can provide quick and easy access of data while the improper one will make an application more complex and time consuming. Good database design is crucial to obtain a sound, consistent database, and-in turn-good database design methodologies are the best way to achieve the right design ${ }^{[37]}$.

Basically, there are two ways to represent database design i.e. (i) graphical and (ii) relational notation ${ }^{[38]}$. Graphically, database can be represented using Entity Relationship diagram or activity diagram i.e. use case diagram. ER-diagram shows how the data are related while use case diagram shows how a user might use a system i.e. the functionality of a system. Use case diagram can be used to illustrate all the availabilities of system rather than simply representing the facts of individual characteristics. The Use case diagrams are implemented in Unified Modeling Language (UML). Relational notation transforms ER-diagram into easily readable form by using table names, attributes and arranging them in specific manner.

Here we have discussed the value chain (Fig 3) for better understanding the process of forecasting in QFD. Later on, we have presented the flow chart (Fig 4) describing the processes involve in the forecasting of QFD. After this, we have included the tabular description (Table 1) of each entity involved in process. Finally, we have portrayed the E-R diagram (Fig 5) required for the development of forecasting tool.

\section{A. The Value Chain of Data Mining Driven Forecasting System for $Q F D$}

The value chain represents the QFD process which is then integrated with DM techniques to generate the forecast for enhancing the competitiveness of product in the marketplace and achieving high customer satisfactions. A value chain will provide us better understanding of the process of data mining driven forecasting system for QFD and help in identifying data requirements for building database system.

Fig. 3 shows the value chain of data mining driven forecasting system for QFD. We call each phase of value chain a forecasting process in that it is essential in its own and involves significant complexities. Each forecasting process involves a set of interaction between user and forecasting system for achieving objectives. Each forecasting process will have different data requirements based on underlying forecasting models supported by forecasting systems. A database designer must completely recognize each forecasting process and discover the data requirements needed to maintain each forecasting process.

\section{B. Flow Chart:}

Flow chart (Fig. 4) gives us a clear cut image of how process are carried out for the development of data mining driven forecasting software tool for QFD. It facilitates designer to consider through many complex issues in advance. This flow chart will be very beneficial for understanding the development process.

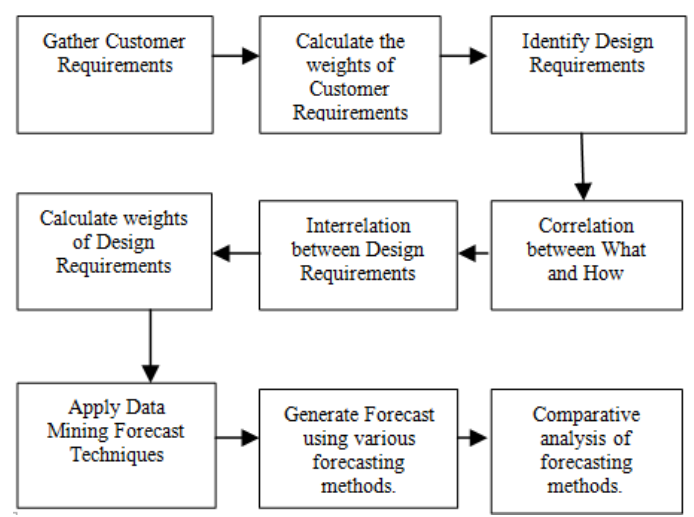

Fig. 3. value chain of Data Mining driven Forecasting system for QFD

\section{Table Names and Their Description:}

For handling the complex data transaction of forecasting tool, we need to maintain the tables. Thus for database designing table handling is mandatory. Here, we require to maintain 22 tables viz; Tbl_Login, Tbl_Product, Tbl_Period, Tbl_Direct_Entry, Tbl_Customer, Tbl_Customer_Requirement, Tbl_Competitor_master, Tbl_Input_Rating, _ol_Input_Improvement_ratio, Tbl_Final_IR, Tbl_DesignMaster, Tbl_Correlation, Tbl_FinalDR, Tbl_Moving_avg, Tbl_wtd_Mvg_Avg, Tbl_Single_expo, Tbl_Double_expo_H\&W, Tbl_CR_Forecast and Tbl_DR_Forecast.

The table(Table 1: table names and their description) shown below includes the name of table required to be maintain in database for developing forecasting tool. Tbl_Product will store the information regarding the product whose customer requirement and design requirement are to be forecasted. Tbl_Period will store the information about how much period we have to store data. Tbl_Direct_Entry will accumulate the information if we have to enter the row weights and column weights directly. The Tbl_Customer will store the customer related information such as number of customer who will rate. Customer will state the customer requirements of the product which will be stored in Tbl_Customer_Requirement. Tbl_Competitor_Master will store the information competitors involved in the process. Each customer will rate each customer requirement which is stored in Tbl_Input_rating . Thereafter the customer requirement of the product will comparatively analyzed with its competitor which is stored in Tbl_Competative_Analysis. The Tbl_Compet_avg will store the average of these ratings w.r.t. customer, customer requirement and competitors. Tbl_Input_impr_ratio will store the goal, improvement ratio and sales point. Then cutomer requirement will be prioritized by calculating row weights and are stored in Tbl_Final_IR. The Tbl_Design_master will store the design requirement stated by technicians to fulfil those customer requirements stated by customer. Then these 
design requirement and customer requirement are correlated and will be stored in Tbl_Correlation. Tbl_Final_DR will store the column weight required to prioritize design requirements. Tbl_Moving_avg, Tbl_wtd_mvg_avg, Tbl_Single_Expo, Tbl_Double_expo, Tbl_Double_H\&W will store the information regarding the moving average, weighted moving, single exponential smoothing, double exponential smoothing, double exponential smoothing using holts and winter method of forecasting respectively. Finally forecasted result of customer requirement and design requirements will bre stored in Tbl_CR_Forecast and Tbl_DR_Forecast resp. Table 1 represents the table names and their corresponding fields along with data type and description.

\section{ER-Diagram}

A database can be better represented in graphical way by using entity relationship diagram. An entityrelationship diagram is a type of data modeling that shows a graphical representation of objects or concepts within an information system or organization and their relationship to one another ${ }^{[39]}$. The major components of ER-diagram are object i.e. entity and the relationship exist among them. The Fig. 5 shown below illustrates the entity relationship diagram for the data mining driven forecasting software tool for QFD. This ER-diagram gives us image of how the tables are connected, what fields are going to be on each tables and what kind of relation they share with each other, if many-to-many, one-to-many or one to one. In the ER diagram, we can view the entities- Product, Period, Direct_entry, Customer, Customer_Requirement, Competitor_master, Own_compet_analysis, Own_avg, Compet_input, Compet_avg, Input_rating, Avg_input_rating, input_improvement_ratio, Final_IR,Design_master, Correlation, Final_DR, Single_expo, Double_expo, Double_expo_H\&W, Moving_avg, Wtd_mvg_avg, CR_forecast and DR_forecast. Relationships exist among these entities, which connect all the entities in the diagram. For example, Customer, Customer_Requirement, and Input_rating are connected via the relationship Generates. Here many Customer rate one customer requirement and generates many input ratings. Similarly, the customer_Requirement Design_master and Correlation are connected via the relationship correlates. In other words, the many Customer_Requirements are correlated with many Design_master to produce many Correlations. Correlation, Final_IR and Final_DR are connected via Gives relationship. Here, many correlations and many Final_IR gives one Final_DR. In a related way, other entities are connected via relationships in a significant way.

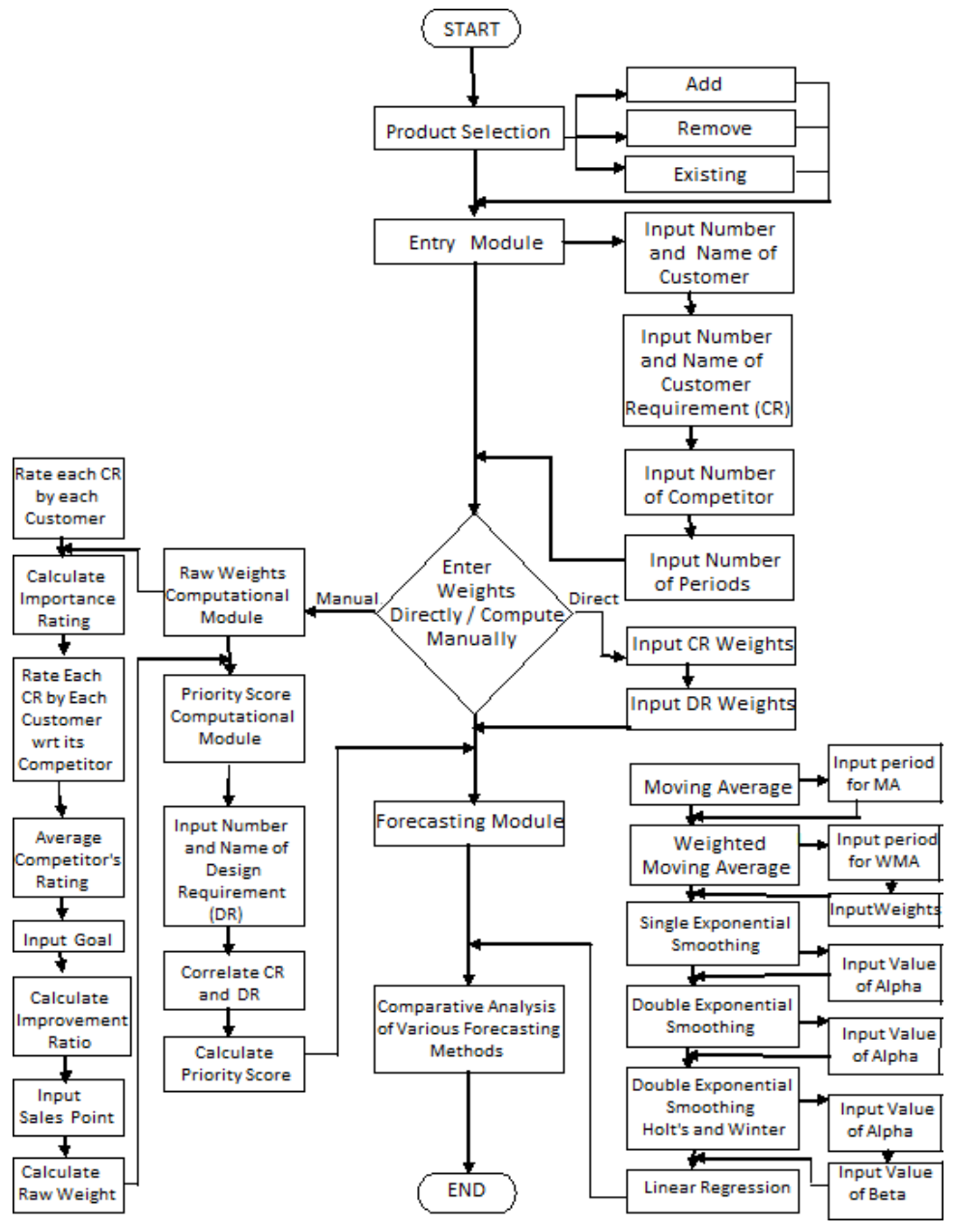

Fig. 4. Flow Chart 


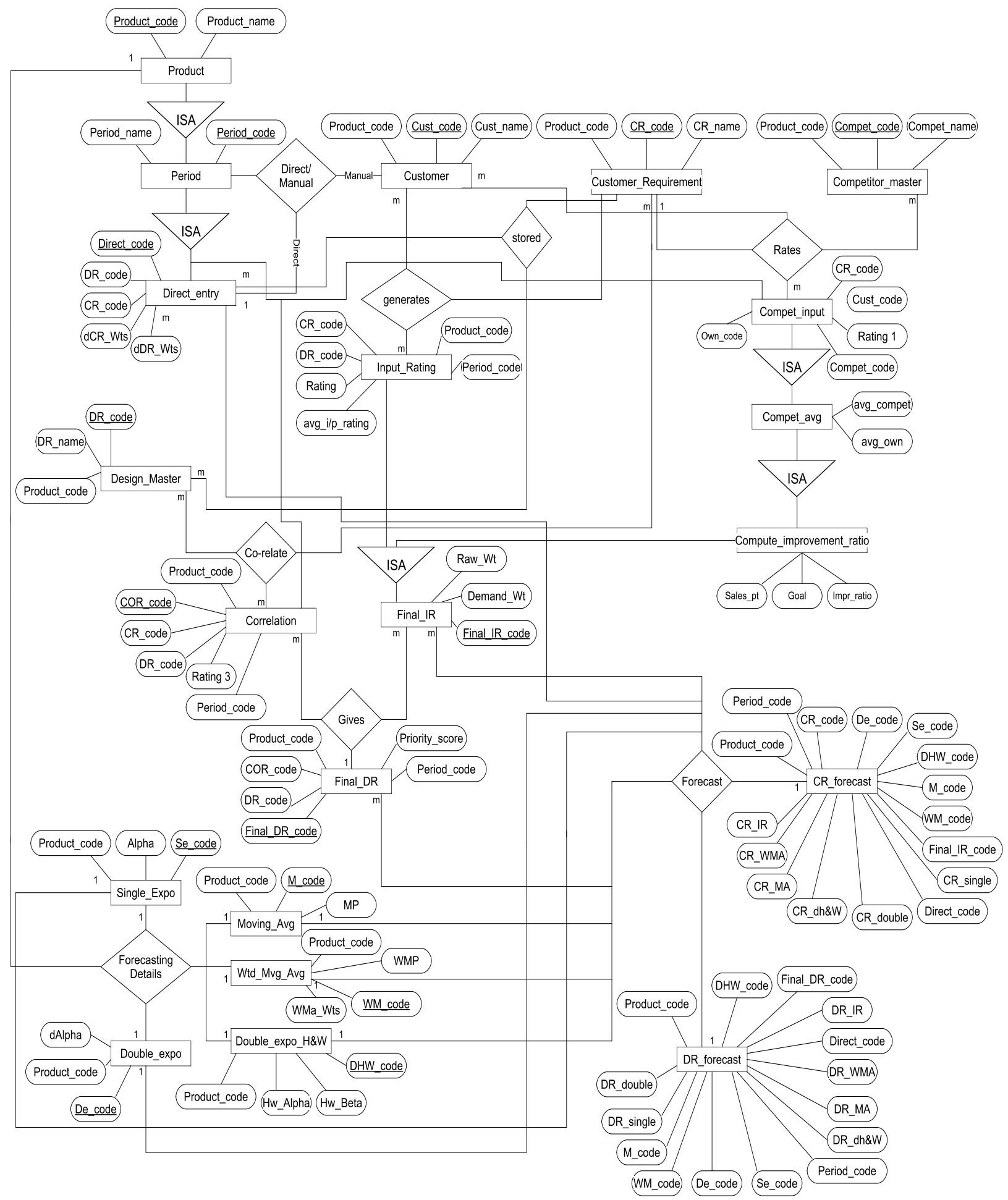

Fig. 5. ER-Diagram

Table 1. Table names, Fields and their description

\begin{tabular}{|l|l|l|l|l|}
\hline Sr. No. & Table Name & Field Name & Data Type & Description \\
\hline \multirow{2}{*}{1.} & \multirow{2}{*}{ Tbl_Login } & User_Name & Text & It describes the name of user. \\
\cline { 3 - 5 } & & Password & Text & It will store the user's password. \\
\hline \multirow{2}{*}{ Tbl_Product } & Product_Code & Text & $\begin{array}{l}\text { This will store the code of the product and will } \\
\text { act as the primary key. }\end{array}$ \\
\cline { 4 - 5 } & & Product_Name & Text & This will save the product's name. \\
\hline
\end{tabular}




\begin{tabular}{|c|c|c|c|c|}
\hline \multirow[t]{3}{*}{3.} & \multirow[t]{3}{*}{ Tbl_Period } & Product_Code & Text & This will store the code of the product. \\
\hline & & Period_Code & Text & $\begin{array}{l}\text { This field will store the code of period and will } \\
\text { act as the primary key. }\end{array}$ \\
\hline & & Period_Name & Text & This will store the name of the period. \\
\hline \multirow[t]{7}{*}{4.} & \multirow[t]{7}{*}{ Tbl_Direct_Entry } & $\underline{\text { D_Code }}$ & Text & $\begin{array}{l}\text { This will store the code of the Direct_entry table. } \\
\text { It will act as the the primary key. }\end{array}$ \\
\hline & & Product_Code & Text & This will store the code of the product. \\
\hline & & Period_Code & Text & This field will store the code of period. \\
\hline & & CR_code & Text & This will store code of customer requirement. \\
\hline & & DR_code & Text & This will store code of design requirement. \\
\hline & & dCR_wts & Number & $\begin{array}{l}\text { This will store the column weights of customer } \\
\text { requirements entered by user. }\end{array}$ \\
\hline & & dDR_wts & Number & $\begin{array}{l}\text { This will store the column weights of design } \\
\text { requirements entered by user. }\end{array}$ \\
\hline \multirow[t]{3}{*}{5 . } & \multirow[t]{3}{*}{ Tbl_Customer } & Product_Code & Text & This will store the code of the product. \\
\hline & & Cust Code & Text & $\begin{array}{l}\text { This will store code of customer and is the } \\
\text { primary key of the Customer table. }\end{array}$ \\
\hline & & Cust_Name & Text & This will store customer's name. \\
\hline \multirow[t]{3}{*}{6.} & \multirow{3}{*}{$\begin{array}{l}\text { Tbl_Customer_Requir } \\
\text { ement }\end{array}$} & Product_Code & Text & This will store the code of the product. \\
\hline & & CR Code & Text & This will store code of customer requirement. \\
\hline & & CustomerRequirement & Text & This will store name of customer requirement. \\
\hline \multirow[t]{3}{*}{7.} & \multirow{3}{*}{$\begin{array}{l}\text { Tbl_Competitor_mast } \\
\text { er }\end{array}$} & Product_code & Text & This will store the code of the product. \\
\hline & & $\underline{\text { Compet Code }}$ & Text & $\begin{array}{l}\text { This will store the code of competitor and will be } \\
\text { primary key for this table. }\end{array}$ \\
\hline & & Compet_Name & Text & This will store the name of competitor. \\
\hline \multirow[t]{6}{*}{8.} & \multirow[t]{6}{*}{ Tbl_Input_Rating } & Product_code & Text & This field will store the code of product. \\
\hline & & Period_code & Text & This will store the code of the period. \\
\hline & & Cust_code & Text & This will store code of customer. \\
\hline & & CR_code & Text & This will store code of customer requirement. \\
\hline & & Rating & Number & $\begin{array}{l}\text { This will store the rating given by customer to } \\
\text { customer requirement for the product. }\end{array}$ \\
\hline & & avg_i/p_rating & Number & $\begin{array}{l}\text { This will store the average of the rating given by } \\
\text { customer to customer requirement for the } \\
\text { product. }\end{array}$ \\
\hline \multirow[t]{7}{*}{9.} & \multirow[t]{7}{*}{ Tbl_Competitor_Input } & Product_code & Text & This will store the code of the product. \\
\hline & & Period_code & Text & This field will store the code of period. \\
\hline & & Cust_code & Text & This will store code of customer. \\
\hline & & CR_code & Text & This will store code of customer requirement. \\
\hline & & Own_Code & Text & This will store code of company's own product. \\
\hline & & Compet_Code & Text & This will store code of compititor. \\
\hline & & Rating 1 & Number & $\begin{array}{l}\text { This will store the rating given by customer to } \\
\text { competitor's customer requirement for the } \\
\text { product. }\end{array}$ \\
\hline \multirow[t]{7}{*}{10.} & \multirow[t]{7}{*}{ Tbl_Compet_Avg } & Product_code & Text & This will store the code of the product. \\
\hline & & Period_code & Text & This field will store the code of period. \\
\hline & & CR_code & Text & This will store code of customer requirement. \\
\hline & & Own_Code & Text & This will store code of company's own product. \\
\hline & & Compet_Code & Text & This will store code of competitor. \\
\hline & & Rating 1 & Number & $\begin{array}{l}\text { This will store the rating given by customer to } \\
\text { competitor's customer requirement for the } \\
\text { product. }\end{array}$ \\
\hline & & Avg_compet & Number & $\begin{array}{l}\text { This will store the average of rating given by } \\
\text { customer to competitor's customer requirement } \\
\text { for the product. }\end{array}$ \\
\hline \multirow[t]{7}{*}{11.} & \multirow{7}{*}{$\begin{array}{l}\text { Tbl_Compute_Improv } \\
\text { ement_ratio }\end{array}$} & Product_code & Text & This will store the code of the product. \\
\hline & & Period_code & Text & This field will store the code of period. \\
\hline & & CR_code & Text & This will store code of customer requirement. \\
\hline & & avg_own & Number & $\begin{array}{l}\text { This will store the average of rating given by } \\
\text { customer to own customer requirement for the } \\
\text { product. }\end{array}$ \\
\hline & & Goal & Number & $\begin{array}{l}\text { This will store the company's goal to achieve the } \\
\text { target. }\end{array}$ \\
\hline & & Impr_ratio & Number & This will store the improvement ratio. \\
\hline & & Sales_pt & Number & $\begin{array}{l}\text { This will store the sales point of customer } \\
\text { requirement. }\end{array}$ \\
\hline
\end{tabular}




\begin{tabular}{|c|c|c|c|c|}
\hline \multirow[t]{9}{*}{12.} & \multirow[t]{9}{*}{ Tbl_Final_IR } & $\underline{\text { F_code }}$ & Text & $\begin{array}{l}\text { This will store the code of the Final_IR table and } \\
\text { will be the primary key for this table. }\end{array}$ \\
\hline & & Product_code & Text & This will store the code of the product. \\
\hline & & Period_code & Text & This field will store the code of period. \\
\hline & & CR_code & Text & This will store code of customer requirement. \\
\hline & & Avg_i/p_rating & Number & $\begin{array}{l}\text { This will store the average of the rating given by } \\
\text { customer to customer requirement for the } \\
\text { product. }\end{array}$ \\
\hline & & Impr_ratio & Number & This will store the improvement ratio. \\
\hline & & Sales_pt & Number & $\begin{array}{l}\text { This will store the sales point of customer } \\
\text { requirement. }\end{array}$ \\
\hline & & Row_wt & Number & $\begin{array}{l}\text { This will store the row weight of customer } \\
\text { requirement. }\end{array}$ \\
\hline & & Demand_wt & Number & $\begin{array}{l}\text { This will store the demand weight of customer } \\
\text { requirement. }\end{array}$ \\
\hline \multirow[t]{3}{*}{13.} & \multirow{3}{*}{ Tbl_DesignMaster } & Product_code & Text & This will store the code of the product. \\
\hline & & DR Code & Text & $\begin{array}{l}\text { It will store the code of design requirement and } \\
\text { will be the primary key. }\end{array}$ \\
\hline & & DR_Name & Text & It will store the name of design requirement. \\
\hline \multirow[t]{5}{*}{14.} & \multirow[t]{5}{*}{ Tbl_Correlation } & Product_code & Text & This will store the code of the product. \\
\hline & & Period_code & Text & This field will store the code of period. \\
\hline & & CR_code & Text & This will store code of customer requirement. \\
\hline & & DR_code & Text & This will store code of design requirement. \\
\hline & & Rating3 & Number & $\begin{array}{l}\text { This will store the rating of correlation between } \\
\text { Customer requirement and design requirement. }\end{array}$ \\
\hline \multirow[t]{7}{*}{15.} & \multirow[t]{7}{*}{ Tbl_FinalDR } & Product_code & Text & This will store the code of the product. \\
\hline & & Period_code & Text & This field will store the code of period. \\
\hline & & CR_code & Text & This will store code of customer requirement. \\
\hline & & Demand_wt & Number & This will store the demand weight. \\
\hline & & DR_Code & Text & This will store code of customer requirement. \\
\hline & & Rating3 & Number & $\begin{array}{l}\text { This will store the rating of correlation between } \\
\text { Customer requirement and design requirement. }\end{array}$ \\
\hline & & Column_wt & Number & This will store the column weight. \\
\hline \multirow[t]{3}{*}{16.} & \multirow[t]{3}{*}{ Tbl_Moving_avg } & $\underline{\text { M_code }}$ & Text & $\begin{array}{l}\text { This will store the code of Moving_avg table and } \\
\text { will be its primary key. }\end{array}$ \\
\hline & & Product_code & Text & This will store the code of the product. \\
\hline & & MP & Number & $\begin{array}{l}\text { This field will store the number of periods of } \\
\text { moving average. }\end{array}$ \\
\hline \multirow[t]{4}{*}{17.} & \multirow[t]{4}{*}{ Tbl_wtd_Mvg_Avg } & WM code & Text & $\begin{array}{l}\text { This will store the code of wtd_Mvg_Avg table } \\
\text { and will be its primary key. }\end{array}$ \\
\hline & & Product_code & Text & This will store the code of the product. \\
\hline & & WMP & Number & $\begin{array}{l}\text { This field will store the number of periods of } \\
\text { weighted moving average. }\end{array}$ \\
\hline & & WMAWts & Number & $\begin{array}{l}\text { This field will store the weights of weighted } \\
\text { moving average. }\end{array}$ \\
\hline \multirow[t]{3}{*}{18.} & \multirow[t]{3}{*}{ Tbl_Single_expo } & $\underline{\text { Se code }}$ & Text & $\begin{array}{l}\text { This will store the code of Single_expo table and } \\
\text { will be its primary key. }\end{array}$ \\
\hline & & Product_code & Text & This will store the code of the product. \\
\hline & & Alpha & Number & $\begin{array}{l}\text { This field will store the value of alpha for single } \\
\text { exponential smoothing. }\end{array}$ \\
\hline \multirow[t]{3}{*}{19.} & \multirow[t]{3}{*}{ Tbl_Double_expo } & $\underline{\text { De code }}$ & Text & $\begin{array}{l}\text { This will store the code of Double_expo table and } \\
\text { will be its primary key. }\end{array}$ \\
\hline & & Product_code & Text & This will store the code of the product. \\
\hline & & dAlpha & Number & $\begin{array}{l}\text { This field will store the value of alpha for double } \\
\text { exponential smoothing. }\end{array}$ \\
\hline \multirow[t]{4}{*}{20.} & \multirow[t]{4}{*}{$\begin{array}{l}\text { Tbl_Double_expo_H } \\
\& \mathrm{~W}\end{array}$} & DHW code & Text & $\begin{array}{l}\text { This will store the code of Double_expo_H\&W } \\
\text { table and will be its primary key. }\end{array}$ \\
\hline & & Product_code & Text & This will store the code of the product. \\
\hline & & dhwAlpha & Number & $\begin{array}{l}\text { This field will store the value of alpha for double } \\
\text { exponential smoothing (Holt and winter). }\end{array}$ \\
\hline & & dhwBeta & Number & $\begin{array}{l}\text { This field will store the value of beta for double } \\
\text { exponential smoothing (Holt and winter). }\end{array}$ \\
\hline
\end{tabular}




\begin{tabular}{|c|c|c|c|c|}
\hline \multirow[t]{16}{*}{21.} & \multirow[t]{16}{*}{ Tbl_CR_Forecast } & Product_code & Text & This will store the code of the product. \\
\hline & & Period_code & Text & This will store the code of the period. \\
\hline & & CR_code & Text & This will store code of customer requirement. \\
\hline & & dCR_wts & Number & $\begin{array}{l}\text { This will store the column weights of customer } \\
\text { requirements entered by user. }\end{array}$ \\
\hline & & M_code & Text & This will store the code of Moving_avg table. \\
\hline & & WM_code & Text & $\begin{array}{l}\text { This will store the code of wtd_Mvg_Avg table } \\
\text { and will be its primary key. }\end{array}$ \\
\hline & & Se_code & Text & This will store the code of Single_expo table. \\
\hline & & De_code & Text & This will store the code of Double_expo table. \\
\hline & & DHW_code & Text & This will store the code of Double_expo_H\&W. \\
\hline & & Row_wt & Number & $\begin{array}{l}\text { This will store the row weight of customer } \\
\text { requirement. }\end{array}$ \\
\hline & & CR_MA & Number & $\begin{array}{l}\text { This field will store the forecast of CR using } \\
\text { Moving Average method. }\end{array}$ \\
\hline & & CR_WMA & Number & $\begin{array}{l}\text { This field will store the forecast of CR using } \\
\text { Weighted Moving Average method. }\end{array}$ \\
\hline & & CR_single & Number & $\begin{array}{l}\text { This field will store the forecast of CR using } \\
\text { Single Exponential smoothing method. }\end{array}$ \\
\hline & & CR_double & Number & $\begin{array}{l}\text { This field will store the forecast of CR using } \\
\text { Double Exponential smoothing method. }\end{array}$ \\
\hline & & CR_dh\&w & Number & $\begin{array}{l}\text { This field will store the forecast of CR using } \\
\text { Double Exponential (Holt \& Winter) smoothing } \\
\text { method. }\end{array}$ \\
\hline & & CR_LR & Number & $\begin{array}{l}\text { This field will store the forecast of CR using } \\
\text { Linear regression method. }\end{array}$ \\
\hline \multirow[t]{16}{*}{22.} & \multirow[t]{16}{*}{ Tbl_DR_Forecast } & Product_code & Text & This will store the code of the product. \\
\hline & & Period_code & Text & This will store the code of the period. \\
\hline & & DR_code & Text & This will store code of design requirement. \\
\hline & & dDR_wts & Number & $\begin{array}{l}\text { This will store the column weights of design } \\
\text { requirements entered by user. }\end{array}$ \\
\hline & & M_code & Text & This will store the code of Moving_avg table. \\
\hline & & WM_code & Text & $\begin{array}{l}\text { This will store the code of wtd_Mvg_Avg table } \\
\text { and will be its primary key. }\end{array}$ \\
\hline & & Se_code & Text & This will store the code of Single_expo table. \\
\hline & & De_code & Text & This will store the code of Double_expo table. \\
\hline & & DHW_code & Text & This will store the code of Double_expo_H\&W. \\
\hline & & Row_wt & Number & $\begin{array}{l}\text { This will store the row weight of Design } \\
\text { requirement. }\end{array}$ \\
\hline & & DR_MA & Number & $\begin{array}{l}\text { This field will store the forecast of DR using } \\
\text { Moving Average method. }\end{array}$ \\
\hline & & DR_WMA & Number & $\begin{array}{l}\text { This field will store the forecast of DR using } \\
\text { Weighted Moving Average method. }\end{array}$ \\
\hline & & DR_single & Number & $\begin{array}{l}\text { This field will store the forecast of DR using } \\
\text { Single Exponential smoothing method. }\end{array}$ \\
\hline & & DR_double & Number & $\begin{array}{l}\text { This field will store the forecast of DR using } \\
\text { Double Exponential smoothing method. }\end{array}$ \\
\hline & & DR_dh\&w & Number & $\begin{array}{l}\text { This field will store the forecast of DR using } \\
\text { Double Exponential (Holt \& Winter) smoothing } \\
\text { method. }\end{array}$ \\
\hline & & DR_LR & Number & $\begin{array}{l}\text { This field will store the forecast of DR using } \\
\text { Linear regression method. }\end{array}$ \\
\hline
\end{tabular}

\section{CONCLUSION}

The well-designed database can contribute to the efficient software system. It can offer quick and correct access of information required by the software and also provides the effective storage system for handling data transactions. The database designed above contains all the information required to be sustained in the forecasting software tool. As QFD and data mining are very complex and tedious processes; thus the computerization of entire system via database will facilitate proficient, convenient, faster and timely maintenance of data. In this paper we have presented the detailed value chain, flow chart, tabular description of schemas and the ER-diagram illustrating the relationships among the entities. Finally, we concluded, this paper will strongly assist the designer and developer understanding the general architecture of database to build up and sustain the data mining driven forecasting software tool for Quality Function Deployment.

\section{REFERENCES}

[1] G. Creech, Building a Relational Database with Microsoft Access. International Association of Administrative Professionals, EFAM, July 2013.

[2] E. E. Karsak, "Fuzzy Multiple Objective Programming Framework to Prioritize Design Requirements in Quality Function Deployment", Computers \& Industrial Engineering, Elsevier, vol. 47, pp. 149-163, 2004.

[3] C. H. Hsu, S. Y. Wang and L. T. Lin. Using Data Mining to Identify Customer Needs in Quality Function Deployment for Software Design. In Proceedings of the 6th WSEAS International Conference on Artificial 
Intelligence, Knowledge Engineering and Data Bases, Corfu Island, Greece, February 16-19, 2007.

[4] F. Olaiya and A. B. Adeyemo, "Application of Data Mining Techniques in Weather Prediction and Climate Change Studies", I.J. Information Engineering and Electronic Business, MECS, vol. 1 pp. 51-59, February 2012.

[5] Y. Akao, Quality Function Deployment: Integrating Customers Requirements into Product Design,. Cambridge. MA: Productivity Press. 1990.

[6] S. Barutçu,"Quality Function Deployment in Effective Website Design:An Application in E-Store Design", Isletme Fakültesi Dergisi, Cilt, vol. 7, no. 1, pp. 41-63, 2006.

[7] C. Kahraman, T. Ertay and G. Buyukozkan, ”A Fuzzy Optimization Model for QFD Planning Process using Analytic Network Approach", European Journal of Operational Research, Elsevier, vol. 171, no. 2, pp. 390411, 2004.

[8] M. C. Lin, C. Y. Tsai, C. C. Cheng, and C. A. Chang, "Using Fuzzy QFD for Design of Low-end Digital Camera", International Journal of Applied Science and Engineering, vol. 2, no. 3, pp. 222-233, 2004.

[9] G. Ioannou, K. C. Pramataris and G.P. Prastacos," A Quality Function Deployment Approach to Web Site Development: Applications for Electronic Retailing" Les Cahiers du Management Technologique, vol. 13, no. 3, 2004.

[10] S. Zaim and M. Sevkli, "The Methodology of Quality Function Deployment with Crisp and Fuzzy Approaches and an Application in the Turkish Shampoo Industry," Journal of Economic and Social Research, vol. 4, no.1, pp. 27-53, 2002.

[11] A. Dhond, A. Gupta and S. Vadhavkar. Data Mining Techniques for optimizing Inventories for Electronic Commerce. KDD 2000, Boston, MA USA, 2000.

[12] P. Pujari and J. B. Gupta, "Exploiting Data Mining Techniques for Improving the Efficiency of Time Series Data using SPSS-CLEMENTINE," Researchers World Journal of Arts, Science \& Commerce vol. 3 no. 2-3, pp. 69-80, April 2012.

[13] X. Zheng and P. Pulli, "Improving Mobile Services Design: A QFD Approach", Computing and Informatics, vol. 26, pp. 369-381, January 2007

[14] R. B. Kazemzadeh, M. Behzadian, M. Aghdasi, and A. Albadvi,'Integration of Marketing Research Techniques into House Of Quality and Product Family Design." The International Journal of Advanced Manufacturing Technology, vol. 41, no. 9-10, pp 1019-1033, April 2009.

[15] A. H. I. Lee, Y. H. Kang and C. Y. Yang, "An Evaluation Framework for Product Planning using FANP, QFD and multi-Choice Goal Programming," International Journal of Production Research, vol. 48, no. 13, 2010.

[16] X. X. Shen, C. K. Tan and M. Xie, "Benchmarking in QFD for Quality Improvement," Benchmarking: An International Journal, vol. 7, pp.282 - 291, 2000.

[17] A. Alemam and S. Li, "Integration of Quality Function Deployment and Functional Analysis for Eco-design", International Journal of Mechanical Engineering and Mechatronics, vol. 2, no. 1, 2014.

[18] S. Telang and C. Vichoray, "Development in Agricultural Tractor Brakes through QFD Application-A Conceptual Analysis," IOSR Journal of Mechanical and Civil Engineering (IOSR-JMCE), pp. 55-59, 2014.

[19] C. Zhang and Z. Fang, "An Improved K-means Clustering Algorithm," Journal of Information \& Computational Science, vol. 10, pp.193-199, January 1, 2013.
[20] R. Hu, "Data Mining in the Application of Criminal Cases Based on Decision Tree," International Journal of Engineering Sciences, vol. 2, no. 2,pp. 24-27, February 2013.

[21] G. C. Onwubolu, "Data Mining using Inductive Modeling Approach", pp. 78-86, 2007.

[22] J. Yang. Research and Design of Hotel Management System Model. International Conference on Education Technology and Information System, 2013.

[23] H. Dev and A. Seth, "MDA based Approach towards Design of Database for Banking System", International Journal of Computer Applications (0975 -8887) vol. 49, no.16, July 2012.

[24] U. A. Umoh, E. O. Nwachukwu, A. A. Umoh, and E. B. Isong, "A Web-Based Database System: An Industrial Application", Research Journal in Engineering and Applied Sciences vol. 1, no. 3, pp. 203-208, 2012.

[25] M. A. Casanova, S. D. J. Barbosa, K. K. Breitman and A. L. Furtado, "Three Decades of Research on Database Design at PUC-Rio", Journal of Information and Data Management, vol. 3, no. 1, pp19-34, February 2012.

[26] I. Adusei, O. Kuljaca and K. Agyepong, "Intelligent Mammography Database Management System for a Computer Aided Breast Cancer Detection and Diagnosis", International Journal of Managing Information Technology (IJMIT), vol.2, no.2, May 2010.

[27] R. S. Khan and M. Saber, "Design of a Hospital-Based Database System (A Case Study of BIRDEM)", International Journal on Computer Science and Engineering (IJCSE), vol. 02, no. 08, pp. 2616-2621,2010.

[28] J. B. Cushing, N. Nadkarn, M. Finch, A. Fiala, E. Murphy-Hill, L. Delcambre and D. Maier, "Componentbased end-user database design for ecologists", Journal of Intelligent Information System, vol. 29, no. 1, pp. 7, 2007.

[29] E. J. L. Lu and Y. Y. Cheng, "Design and implementation of a mobile database for Java phones", Computer Standards \& Interfaces, vol. 26, pp 401-410, 2004.

[30] I. Y. Song and K. Y. Whang. Database Design for RealWorld E-Commerce Systems. IEEE Computer Society Technical Committee on Data Engineering, 2000.

[31] D. R. McCarthy and U. Dayal. The Architecture of an Active Data Base Management System. Association for Computing Machinery, 1989.

[32] S. Finkelstein, M. Schkolnick and P. Tiberio. Physical database design for relational databases. ACM Transactions on Database Systems (TODS), vol. 13, no. 1, pp. 91-128, March 1988.

[33] E. Kwan. Designing Databases using a Customized SAS/AF® Frame Entry Application. Ischemia Research and Education Foundation, San Francisco, Callifornia, USA.

[34] I. Sentarli, A. Erdursun and Deha Caman. Development of a Database Management System Design Involving Quality Related Costs. Lund University, Campus Helsingborg.

[35] L. Ying and C. L. Ling, "Research on Spatial Database Design and Tuning Based on Oracle and ARCSDE".

[36] G. Wiederhold. Databases in Healthcare. National Institutes of Health, Stanford Computer Science Department, Report No. STAN-CS-80-790

[37] A. Badia, and D. Lemire ," A Call to Arms: Revisiting Database Design",SIGMOD Record, vol. 40, no. 3, September 2011.

[38] http://home.ubalt.edu/abento/300/DBdesign/ retrieved on 31 November 2014.

[39] http://searchcrm.techtarget.com/defination/entityrelatioship-diagram/ retrieved on 14 December 2014. 


\section{Authors' profiles}

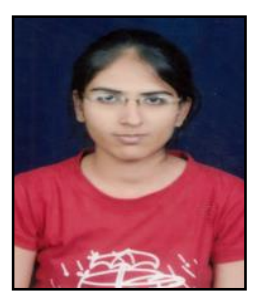

Shivani K. Purohit(B.E.)* recieved her B.E. degree from Manoharbhai Patel Institute of Engineering and Technology (MIET), Gondia, India. She is research scholar and pursuing her M.E. by Research in Computer Science and Technology, from MIET, Nagpur University, India. Her areas of interest are Data mining, Quality Function Deployment, Web Technlogies, Software, Database, Artificial Intelligence (AI) etc.

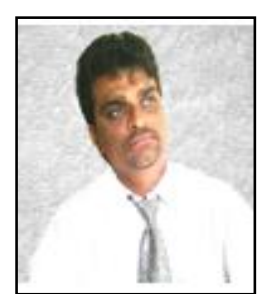

Ashish K. Sharma(B.E., M.E.) is presently working as an Asst. Prof. in Manoharbhai Patel Institute of Engineering and Technology(MIET), Gondia, India. Prior to this, he was associated with IT industry in the areas of Training, Software and Web Application Development. He has an experince of more than 16 years in Academic, Industrial and Software
Development field. He is an Microsoft Certified Professional (MCP) and also holds Brainbench certification. He has more than 15 research papers and articles published Nationally and Internationally in various reputed Journals and Conferences to his credit which includes Inderscience and Actapress Journals. His thrust areas include Software Engineering, Software and Web Development, Databases, Data Mining, Image Processing,Windows Forensics, Fuzzy Logic etc.

How to cite this paper: Shivani K. Purohit, Ashish K. Sharma,"Database Design for Data Mining Driven Forecasting Software Tool for Quality Function Deployment", IJIEEB, vol.7, no.4, pp.39-50, 2015. DOI: 10.5815/ijieeb.2015.04.06 